\title{
Metodologia e aplicação da citometria de fluxo na hematologia veterinária
}

\author{
Flow cytometry methodology and application in the veterinary hematology
}

\author{
Ana Paula Massae Nakage ${ }^{1}$ Aureo Evangelista Santana ${ }^{2}$ \\ Maria Luisa Buffo de Cápua ${ }^{3}$ Patrícia Sampaio Coelho ${ }^{4}$
}

\section{RESUMO}

A citometria de fluxo é um método emergente na medicina veterinária que permite a identificação e quantificação de células em suspensão. Apesar do custo elevado e da necessidade de técnicos especializados para realização da avaliação citofluorométrica, esta técnica tem uma ampla aplicação na hematologia veterinária, incluindo a avaliação de células-tronco hematopoiéticas, eritrócitos, leucócitos e plaquetas. O grande potencial de aplicação clínica da citometria de fluxo inclui a quantificação das células $\mathrm{CD} 34^{+}$como indicação da capacidade de reconstituição hematopoiética após o transplante de células-tronco e das subpopulações linfocitárias para avaliação da resposta imune frente aos transplantes e às doenças que acometem os animais. Projetos científicos sobre a avaliação citofluorométrica das células-tronco e subpopulações linfocitárias de cães têm sido desenvolvidos com sucesso por pesquisadores da área de hematologia veterinária na Universidade Estadual Paulista (UNESP), Campus de Jaboticabal. Portanto, no futuro, a citometria de fluxo deve se tornar uma técnica de rotina em laboratórios veterinários no Brasil.

Palavras-chave: citometria de fluxo, medicina veterinária hematologia, células-tronco, subpopulações linfocitárias.

\begin{abstract}
Flow cytometry is an emergent method in veterinary medicine which provides the identification and quantification of the suspension cells. However the high costs and the trained technical specialist required the flow cytometry has a wide variety of applications in the veterinary hematology including hematopoietic stem cells erythrocyte, leukocyte and platelet evaluation. The important clinical application of the flow cytometry is the $\mathrm{CD}_{3} 4^{+}$quantification to hematopoietic reconstitution after stem cell transplant and lymphocyte subsets to evaluate the immune reply to tissue or organ transplant and animals diseases. Scientific assays about flow cytometry evaluation of the stem cell and lymphocyte subsets of dogs have been performed successfully by veterinary hematology scientists in the Universidade Estadual Paulista (UNESP), Campus Jaboticabal. Then, in the future, it would become a usual technique in the veterinarian's laboratories in the Brazil.
\end{abstract}

Key words: flow cytometry, veterinary medicine, hematology, stem cell, lymphocyte subsets.

\section{INTRODUÇÃO}

A citometria de fluxo é um recurso emergente na medicina veterinária que permite uma

${ }^{1}$ Curso de Pós-graduação em Medicina Veterinária, Área de Concentração em Clínica Médica Veterinária, Nível Doutorado, Faculdade de Ciências Agrárias e Veterinárias (FCAV), Universidade Estadual Paulista (Unesp), Campus de Jaboticabal. Autor para correspondência: Av. João Fiúsa, 1757, apto 12, 14024-250, Ribeirão Preto, São Paulo, Brasil. E-mail: apnkg@ hotmail.com. ${ }^{2}$ FCAV, Unesp, Campus de Jaboticabal, São Paulo, Brasil.

${ }^{3}$ Pós-graduação em Medicina Veterinária, Área de Concentração em Clínica Médica Veterinária, Nível Mestrado, FCAV, Unesp, Campus de Jaboticabal, São Paulo, Brasil.

${ }^{4}$ Pós-graduação em Medicina Veterinária, Área de Concentração em Patologia Animal, Nível Mestrado, FCAV, Unesp, Campus de Jaboticabal, São Paulo, Brasil. 
análise rápida, objetiva e quantitativa de células em suspensão (FALDYNA et al., 2001). As células da amostra em suspensão são marcadas com anticorpos monoclonais específicos ligados a fluorocromos, que permitem a identificação e a quantificação de células pelo tamanho, granulosidade e intensidade de fluorescência (ROITT et al., 1999). Apesar do alto custo e da necessidade de técnicos especializados para realização da avaliação citofluorométrica, esta técnica tem sido aplicada em diversos projetos científicos relacionados à medicina veterinária no Brasil. A citometria de fluxo tem uma ampla aplicação na hematologia veterinária, incluindo a identificação de células-tronco hematopoiéticas, contagens celulares diferenciais da medula óssea, quantificação de reticulócitos, pesquisa de eritroparasitas, detecção de anticorpos anti-eritrocitários, contagem diferencial de leucócitos, imunofenotipagem de linfócitos e contagem de plaquetas reticuladas.

O grupo de pesquisa do laboratório de patologia clínica veterinária da Faculdade de Ciências Agrárias e Veterinárias (FCAV) da Universidade Estadual Paulista (UNESP), Campus de Jaboticabal (SP), constituído por docente, graduandos e pósgraduandos em medicina veterinária, tem realizado projetos científicos relacionados à citometria de fluxo desde 2000. Entretanto, devido ao elevado custo do citômetro de fluxo, as análises citofluorométricas têm sido realizadas no laboratório de citometria de fluxo do Hemocentro de Ribeirão Preto/SP, localizado no Centro de Terapia Celular (CTC) da Faculdade de Medicina de Ribeirão Preto (FMRP), Universidade de São Paulo (USP). Os projetos de pesquisa desenvolvidos com sucesso pelo grupo supracitado estão relacionados com a quantificação de célulastronco (NAKAGE et al., 2004) e subpopulações linfocitárias do sangue do cordão umbilical de cães. Além disso, vários experimentos relacionados com a hematologia veterinária estão em andamento, demonstrando a importância da citometria de fluxo.

O objetivo desta revisão bibliográfica é demonstrar a metodologia e a aplicação da citometria de fluxo na hematologia veterinária, devido à crescente importância desta técnica na medicina veterinária no Brasil.

\section{METODOLOGIA DA CITOMETRIA DE FLUXO}

\section{Citômetro de fluxo}

O citômetro de fluxo é um aparelho utilizado para avaliação da emissão de fluorescência das células (FACS - Fluorescence Activated Cell Sorter). Alguns aparelhos são capazes de separar fisicamente as células, de acordo com as características citométricas (ROITT et al., 1999).

As células da amostra em suspensão são marcadas com reagentes fluorescentes específicos para detecção de moléculas de superfície e são introduzidas numa câmara de fluxo vibratória. O fluxo de células que atravessa a câmara é envolvido por uma solução tampão, sendo que 500 a 4000 células ou partículas passam em fila simples por segundo por meio do sensor eletrônico. O fluxo é iluminado por laser de argônio (azul), que tem uma energia de luz incidente de 488nm. Cada célula é avaliada com relação ao tamanho (dispersor de luz anterior) e granulosidade (dispersor de $90^{\circ}$ ) e para intensidade de fluorescência para detecção de antígenos de superfície diferentes (imunofenotipagem). A vibração do fluxo celular provoca o rompimento em gotículas que podem ser carregadas eletricamente e, a partir daí, dirigidas por placas de deflexão eletromagnética para serem coletadas em diferentes populações celulares de acordo com os parâmetros medidos, sob controle de um computador (ROITT et al., 1999).

Fundamentos da técnica da citometria de fluxo

A citometria de fluxo pode ser usada para identificação de determinadas células em suspensão, promovendo a identificação e a quantificação de células pelo tamanho, granulosidade e intensidade de fluorescência destas células (ROITT et al., 1999).

A avaliação do tamanho relativo da célula ("Forward scatter - FSC") e da granulosidade ou complexidade interna da célula ("Side Scatter - SSC") permite a classificação dos leucócitos em linfócitos, monócitos e granulócitos (GRINDEM, 1996). A imunofenotipagem consiste no isolamento de populações de células distintas com diferentes antígenos de superfície marcados com anticorpos fluorescentes específicos (ROITT et al., 1999). A avaliação da intensidade de fluorescência ocorre para detecção de antígenos de superfície diferentes marcados com anticorpos monoclonais específicos ligados a compostos químicos fluorescentes ou fluorocromos (GRINDEM, 1996).

Os anticorpos monoclonais são os reagentes de escolha devido à sua especificidade, reação cruzada mínima e reprodutibilidade (KEREN, 1994). O termo CD (Cluster Designation = denominação de grupamento) é utilizado para denominar os anticorpos monoclonais criados em diferentes laboratórios de todo o mundo contra antígenos leucocitários humanos (ROITT, 1999).

Alguns "workshops” têm sido organizados para classificar os antígenos que identificam os tipos 
celulares com um número do $\mathrm{CD}$ correspondente à nomenclatura humana de diversos animais domésticos, incluindo, os cães (COBBOLD \& METCALF, 1994), suínos (SAALMULLER, 1996), eqüinos (LUNN et al., 1996) e ruminantes (NAESSENS et al., 1997). Determinados anticorpos monoclonais específicos para felinos foram identificados (ACKLEY et al., 1990; ACKLEY \& COOPER, 1992; WILLETT et al., 1994; WOO \& MOORE, 1997). Alguns anticorpos monoclonais específicos para cães e gatos estão disponíveis comercialmente (BYRNE et al., 2000).

\section{Preparação da amostra}

A coleta e o processamento da amostra variam de acordo com o tipo celular a ser analisado, o local de onde é proveniente e o método de ensaio. Vários anticoagulantes como o EDTA, citrato de sódio e heparina têm sido utilizados com sucesso. O volume de amostra necessário para análise, geralmente, é de $100 \mu \mathrm{L}$ de sangue periférico ou medula óssea. Células danificadas ou mortas alteram as propriedades de tamanho e granulosidade nos gráficos e ligação inespecífica de anticorpos monoclonais. Portanto, o sangue deve ser refrigerado e processado até 24 horas após a coleta da amostra (WEISS, 2002).

O método básico do processamento de amostras por meio da citometria de fluxo é comum na maioria dos ensaios (QUIRKE \& DYSON, 1986). Geralmente, as células são incubadas por 30 a 60 minutos com um anticorpo marcado com fluorocromo ou somente com um anticorpo monoclonal específico. Se o anticorpo monoclonal é marcado com o fluorocromo, a suspensão celular é lavada, ressuspendida em solução tampão e analisada. Se o anticorpo primário não é marcado, após lavar a suspensão celular, é adicionado um anticorpo anticamundongo. O anticorpo secundário se liga proporcionalmente à quantidade de anticorpo primário que é ligado. Após a remoção do anticorpo secundário em excesso, pela lavagem, a amostra é analisada (WEISS, 2002).

A detecção e enumeração de reticulócitos caninos são realizadas com o fluorocromo thiazole orange (ABBOT \& McGRATH, 1991; EVANS \& FAGG, 1994), que é um fluorocromo permeável à membrana dos reticulócitos que se liga aos ácidos nucléicos, formando um complexo nucleotídeo fluorescente reagente com emissão de fluorescência a 530nm (FERGUSON et al., 1990). O sangue total incubado com thiazole orange por 30 minutos é analisado. As células são dispostas nos gráficos de fluorescência verde versus tamanho relativo da célula e um quadro avalia a porcentagem de eritrócitos com intensidade de fluorescência elevada (WEISS, 2002). A estabilidade da amostra a $4^{\circ} \mathrm{C}$ ocorre durante 96 horas após a coleta do sangue total adicionado de EDTA e a estabilidade do fluorocromo thiazole orange é de 5,5 horas após a marcação a $20^{\circ} \mathrm{C}$ em ambiente escuro (ABBOT \& McGRATH, 1991).

Os leucócitos podem ser analisados no sangue total com anticoagulante ou podem ser isolados pelo uso da centrifugação por gradiente de densidade. O sangue total evita as alterações celulares associadas à centrifugação por gradiente de densidade. Geralmente, os eritrócitos são removidos pela adição de tampão de lise de hemácias (WEISS, 2002). As variações no tamanho e na granulosidade permitem a classificação dos leucócitos em linfócitos, monócitos e granulócitos. É importante e ideal que as subpopulações linfocitárias T CD4 e CD8 sejam preservadas, enquanto outros componentes que possam interferir na identificação desses linfócitos sejam eliminados. Desta forma, o método recomendado para preparação das amostras, segundo as diretrizes do National Institute of Allergy and Infectious Diseases, é a utilização da lise do sangue total, visto que os métodos de separação de células linfocitárias por diferença de gradiente de densidade pelo Ficoll ou Histopaque requerem maior volume de sangue e as alterações nas subpopulações linfocitárias são maiores (PAXTON et al., 1989). BYRNE et al. (2000) observaram que o isolamento de leucócitos do sangue periférico pelo método de lise do sangue total produziu fragmentos, dificultando a padronização. Porém, segundo FALDYNA et al. (2001), a lise de hemácias do sangue total é o método de escolha, particularmente na medicina de pequenos animais onde a quantidade de sangue colhida é limitada. $\mathrm{O}$ anticoagulante recomendado é o ácido etilenodiaminotetracético dissódico (EDTA), que proporciona uma boa separação das distintas populações leucocitárias e permite que as amostras possam ser analisadas satisfatoriamente dentro de um período de 24 horas (PAXTON et al., 1989). O transporte para o laboratório e a estocagem das amostras devem ser realizados sob uma temperatura de $22^{\circ} \mathrm{C}$, visto que a preservação do sangue na temperatura de $4^{\circ} \mathrm{C}$ ocasiona uma perda significativa de linfócitos T auxiliares (WEIBLEN et al., 1983).

A análise de anticorpos anti-plaquetários pode ser realizada pelos métodos direto e indireto. $\mathrm{Na}$ avaliação direta, as plaquetas são isoladas do sangue, lavadas para remoção do plasma residual e incubação com anti-IgG ou anti-IgM espécie-específico. No método indireto, plaquetas de cães fixadas com 
paraformaldeído são incubadas com fluoresceína ligada à IgG ovelha anti-cão.

\section{APLICAÇÃO DA CITOMETRIA DE FLUXO NA HEMATOLOGIA}

Avaliação das células-tronco hematopoiéticas

As células-tronco hematopoiéticas derivadas da medula óssea, do fígado fetal, do cordão umbilical ou, até mesmo, do sangue periférico, podem ser identificadas com o auxílio de um anticorpo monoclonal dirigido contra o antígeno de superfície CD34 (HUSS et al., 2000).

A quantificação das células-tronco CD34+ pela citometria de fluxo nos animais domésticos é possível apenas na espécie canina, devido à produção de anticorpos monoclonais específicos para CD34 canino por McSWEENEY et al. (1998). A marcação com anticorpo monoclonal canino CD34 e sua respectiva contagem por meio da análise no citômetro de fluxo permitem a identificação e quantificação das células-tronco na medula óssea (McSWEENEY et al., 1996; McSWEENEY et al., 1998; BRUNO et al., 1999; BRUNO et al., 2001; NIEMEYER et al., 2001; HARTNETT et al., 2002) e no sangue do cordão umbilical de cães (NAKAGE et al., 2004).

A contagem de células $\mathrm{CD}^{3} 4^{+}$, como indicador da capacidade de reconstituição das células sanguiíneas, foi proposta inicialmente por SIENA et al. (1989) e, atualmente, a quantificação de células CD34+ pela citometria de fluxo tem sido amplamente adotada para realização de transplante de células-tronco (HUSS et al., 2000). A quantidade de CD $34^{+}$recomendada para transplantes em cães varia de 1,2 a $3,4 \times 10^{6} \mathrm{~kg}^{-1}$ de peso (GENGOZIAN, 2000). Cães que receberam transplante de medula óssea com menos de $1,0 \times 10^{6}$ células CD34+ $\mathrm{kg}^{-1}$ apresentaram lenta recuperação da celularidade neutrofílica e plaquetária (BRUNO et al., 1999) e linfocítica (HARTNETT et al., 2002).

O transplante de sangue periférico mobilizado com fatores de crescimento hematopoiéticos, tais como, o fator estimulante de colônia granulocitária ("granulocyte-colony stimulating factor" ou G-CSF) ou o fator de célulatronco ("stem cell factor" ou SCF) permite a mobilização de células-tronco hematopoiéticas da medula óssea para o sangue periférico de cães. O transplante de sangue periférico mobilizado com 4,6 x $10^{6}$ células $\mathrm{CD}^{3} 4^{+} \mathrm{kg}^{-1}$ permitiu a reconstituição hematopoiética dos cães (SANDMAIER et al., 1996), sendo uma alternativa ao transplante de medula óssea, devido à facilidade na colheita e à rapidez de recuperação granulocitária e plaquetária.
A quantidade de células-tronco no SCU de cães $\left(3,38 \pm 2,72\right.$ células CD34+ $\left.\times 10^{6} \mathrm{~kg}^{-1}\right)$ verificada por NAKAGE et al. (2004) foi semelhante àquela obtida na medula óssea (BRUNO et al., 1999; HARTNETT et al., 2002; CREEVY et al., 2003) e no sangue periférico mobilizado (SANDMAIER et al., 1996; SANDMAIER et al., 2003) de cães adultos, sendo a quantidade recomendada $\left(1,2\right.$ a $\left.3,4 \times 10^{6} \mathrm{~kg}^{-1}\right)$, para reconstituição hematopoiética em cães (GENGOZIAN, 2000).

$\mathrm{O}$ transplante de células $\mathrm{CD} 34^{+}$do sangue periférico e medula óssea revela o potencial terapêutico das células-tronco em cães com linfoma (APPELBAUM et al., 1986; ABRAMS-OGG et al., 1993), doenças genéticas (BREIDER et al., 1989; GOERNER et al., 1999; HARTNETT et al., 2002; CREEVY et al., 2003; STELZNER et al., 2003), doenças do miocárdio (KOVACIC et al., 2004; VULLIET et al., 2004), doenças vasculares (BHATTACHARYA et al., 2000; HE et al., 2003; MATSUMURA et al., 2003) e doenças do tecido ósseo (ARINZEH et al., 2003; DE KOK et al., 2003).

Portanto, a identificação e quantificação das células $\mathrm{CD} 4^{+}$nos cães, pela técnica de citometria de fluxo, avalia a capacidade de reconstituição hematopoiética das células-tronco caninas para realização de transplantes de medula óssea e permite o emprego do modelo canino em várias propostas experimentais e terapêuticas sobre células-tronco, que propiciam informações pré-clínicas nos transplantes de medula óssea em humanos.

\section{Avaliação da medula óssea}

As técnicas de citometria de fluxo têm sido utilizadas para determinar a contagem diferencial de células da medula óssea e a maturação de megacariócitos, quantificar a taxa de proliferação celular e detectar e diferenciar leucemias e síndromes mielodisplásicas (WEISS, 2002).

A contagem diferencial de células da medula óssea de cães e gatos por meio da citometria de fluxo permite a identificação de populações de neutrófilos segmentados e bastonetes, metamielócitos, células mielóides imaturas, células eritróides imaturas e células eritróides maduras. Os linfócitos não podem ser quantificados uma vez que se sobrepõem aos eritrócitos maduros; porém o uso de anticorpos monoclonais linfócito-específicos permite a quantificação dessas células (WEISS, 2002). A superestimação de células eritróides maduras pode ocorrer devido à presença de linfócitos na contagem das referidas células. Porém, o efeito é pequeno, pois os linfócitos representam menos de 5\% das células da medula óssea (WEISS et al., 2000). A contagem diferencial de células da medula óssea pela expressão 
do CD45 e da complexidade intracelular foi realizada em cães (FALDYNA et al., 2003; WEISS, 2004) e gatos (WEISS et al., 2000).

A quantificação das subpopulações linfocitárias da medula óssea pela citometria de fluxo é fundamental no monitoramento do paciente após o transplante. O transplante alogênico de medula óssea tem sido utilizado em humanos no tratamento de diversas doenças como anemia aplástica, desordens das células vermelhas, imunodeficiências congênitas e alterações malignas do sangue. A quantidade de células presente na medula óssea é um fator importante no sucesso do transplante, uma vez que as subpopulações de linfócitos do doador mediam um delicado balanço entre rejeição e desenvolvimento da doença do enxerto versus o hospedeiro após o transplante alogênico de células-tronco (ROCHA et al., 2001).

\section{Avaliação dos eritrócitos}

A análise dos eritrócitos pode ser realizada usando sangue total com anticoagulante ou com hemácias isoladas da camada eritrocitária após a centrifugação (WEISS, 2002). As aplicações da citometria de fluxo na avaliação dos eritrócitos consistem na quantificação de reticulócitos (DAVIS \& BIGELOW, 1989), pesquisa de eritroparasitas (WYATT et al., 1991; SHIONO et al., 2004) e detecção de anticorpos anti-eritrocitários (WILKERSON et al., 2000). A quantificação de reticulócitos pela citometria de fluxo é mais precisa do que a contagem manual em felinos (REAGAN et al., 1992) e cães (ABBOT \& McGRATH, 1991). A citometria de fluxo tem sido aplicada na pesquisa de eritroparasitas, tais como, Babesia bovis (WYATT et al., 1991) e Theileria sergenti (SHIONO et al., 2004) em bovinos.

Avaliação dos leucócitos

A imunofenotipagem de linfócitos é uma aplicação comum da citometria de fluxo em imunohematologia de seres humanos, e tem sido utilizada para estudar os efeitos de doenças e modificações do sistema imune nas populações de linfócitos. Na medicina veterinária, essa técnica vem começando a ser utilizada a fim de avaliar a apoptose, a progressão das infecções pelos vírus da imunodeficiência felina e da leucemia felina, a resposta de transplantes de órgãos em modelos caninos, a resposta imunológica frente às infecções (BYRNE et al., 2000) e ao tratamento quimioterápico de animais acometidos por leucemias e linfomas (RIVAS et al., 1996).
Em relação aos anticorpos monoclonais que identificam os antígenos leucocitários caninos, estes foram definidos durante o "Primeiro Workshop Internacional de Antígeno Leucocitário Canino" (CLAW - First Canine Leukocyte Antigen Workshop), ocorrido em Cambridge (U.K.) em 1993 (COBBOLD \& METCALFE, 1994). No supracitado Workshop, definiu-se o CD5 como principal marcador de superfície para todos os linfócitos T de cães, o CD4 como marcador de linfócitos T auxiliares e o CD8 como marcador de linfócitos $\mathrm{T}$ citotóxicos (COBBOLD \& METCALFE, 1994).

A análise dos linfócitos pela citometria de fluxo deve ser acompanhada pelas contagens totais e diferenciais de leucócitos. A quantidade absoluta das subpopulações linfocitárias é determinada pelas porcentagens da citometria de fluxo, o valor total de leucócitos e o valor diferencial relativo de linfócitos. É importante conhecer a distribuição normal das populações de linfócitos em animais sadios para aplicar a citometria de fluxo e utilizá-la para definir doenças, monitorar seu progresso e auxiliar no prognóstico (BYRNE et al., 2000).

A distribuição das subpopulações linfocitárias caninas varia com a idade, sendo que a porcentagem de células $\mathrm{T}$ aumenta com a idade (FALDYNA et al., 2001; HOGENESCH et al., 2004). O valor médio de CD4 (45\%) foi maior do que o de CD8 $(28,8 \%)$ no sangue periférico de cães Beagles com 18 meses de idade (BYRNE et al., 2000).

Avaliação das plaquetas

A amostra mais freqüentemente utilizada para avaliação citofluorométrica das plaquetas é o plasma rico em plaquetas (WEISS, 2000). A citometria de fluxo tem sido utilizada na contagem de plaquetas imaturas (WILKERSON et al., 2001), plaquetas ativadas (ABRAMS \& SHATTIL, 1991) e análise de anticorpos anti-plaquetários (WANER et al., 1995).

A identificação de plaquetas imaturas ou reticuladas, assim como de reticulócitos, é realizada por meio da detecção do aumento do conteúdo de ácido ribonucléico (WEISS \& TOWNSEND, 1998). A contagem de plaquetas imaturas é utilizada para definir se a trombocitopenia é causada por redução na produção ou aumento no consumo/destruição de plaquetas (RUSSEL et al., 1997). A maioria dos cães com contagem elevada de plaquetas reticuladas apresenta trombocitopenia devido ao alto consumo ou destruição de plaquetas (WEISS, 2000). 
Os testes de detecção de plaquetas circulantes ativadas incluem a ligação de fibrinogênio às plaquetas, ligação de anticorpos monoclonais para ativação dependente de marcadores na superfície da plaqueta, além da detecção de micropartículas de plaquetas, da alteração da forma e de agregados de plaquetasleucócitos (ABRAMS \& SHATTIL, 1991; DORE et al., 1993; RUF \& PATSCHEKE, 1995; WEISS et al., 1997; MORITZ et al., 2003).

Resultados positivos de anticorpos antiplaquetários foram obtidos em $67 \%$ dos cães com suspeita de trombocitopenia imunomediada (KRISTENSEN et al., 1994) e em eqüinos com trombocitopenia imunomediada (McGURRIN et al., 2004). Além disso, testes positivos em cães podem indicar erliquiose (WANER et al., 1995).

\section{CONCLUSÃO}

A metodologia da citometria de fluxo, apesar do alto custo e da necessidade de técnicos especializados, permite uma análise rápida, eficiente e quantitativa de células em suspensão. Esta técnica emergente tem ampla aplicação na hematologia veterinária, sendo que projetos científicos sobre a avaliação citofluorométrica das células-tronco e subpopulações linfocitárias de cães têm sido desenvolvidos com sucesso por pesquisadores da área de hematologia veterinária na Universidade Estadual Paulista (UNESP), Campus de Jaboticabal. Portanto, no futuro, a citometria de fluxo deve se tornar uma técnica aplicada em laboratórios veterinários no Brasil.

\section{APOIO FINANCEIRO}

Fundação de Amparo à Pesquisa do Estado de São Paulo - FAPESP (processos 01/01017-7 e 01/01016-0).

\section{REFERÊNCIAS}

ABBOT, D.L.; McGRATH, J.P. Evaluation of a flow cytometric counting procedure for canine reticulocytes by use of thiazole orange. American Journal of Veterinary Research, Chicago, v.52, n.5, p.723-727, 1991.

ABRAMS-OGG, A. et al. Clinical and pathological findings in dogs following supralethal total body irradiation with and without infusion of autologous long-term marrow culture cells. Canadian Journal of Veterinary Research, Ottawa, v.57, n.2, p.79-88, 1993.

ABRAMS, C.; SHATTIL, S.J. Immunological detection of activated platelets in clinical disorders. Thrombosis and Haemostasis, Stuttgard, v.65, n.5, p.467-473, 1991 .
ACKLEY, C.D.; COPPER, M.D. Characterization of a feline T-cell-specific monoclonal antibody reactive with a CD5-like molecule. American Journal of Veterinary Research, Chicago, v.53, n.4, p.466-471, 1992.

ACKLEY, C.D. et al. Identification of a CD4 homologue in the cat. Tissue Antigens, Copenhagen, v.35, n.2, p.92-98, 1990

APPELBAUM, F.R. et al. Cure of malignant lymphoma in dogs with peripheral blood stem cell transplantation. Transplantation, Baltimore, v.42, n.1, p.19-22, 1986.

ARINZEH, T.L. et al. Allogeneic mesenchymal stem cells regenerate bone in a critical-sized canine segmental defect. Journal of Bone and Joint Surgery American Volume, Boston, v.85-A, n.10, p.1927-1935, 2003.

BHATTACHARYA, V. et al. Enhanced endothelization and microvessel formation in polyester grafts seeded with $\mathrm{CD} 34^{+}$bone marrow cells. Blood, New York, v.95, n.2, p.581-585, 2000.

BREIDER, M.A. et al. Long terms effects of bone marrow transplantation in dogs with mucopolysaccharidosis. American Journal of Pathology, Philadelphia, v.134, n.3, p.677-692, 1989 .

BRUNO, B. et al. CD $34^{+}$selected bone marrow grafts are radioprotective and establish mixed chimerism in dogs given high dose total body irradiation. Transplantation, Baltimore, v.68, n.3, p.338-344, 1999.

BRUNO, B. et al. Purified canine CD34+Lin- marrow cells transduced with retroviral vectors give rise to long-term multilineage hematopoiesis. Biology and Blood Marrow Transplantation, Baltimore, v.7, n.10, p.543-551, 2001.

BYRNE, K.M. et al. A standardized gating technique for the generation of flow cytometry data for normal canine and normal feline blood lymphocytes. Veterinary Immunology and Immunopathology, Amsterdam, v.73, n.2, p.167-182, 2000.

COBBOLD, S.; METCALFE, S. Monoclonal antibodies that define canine homologues of human $\mathrm{CD}$ antigens: summary of the First International Canine Leukocyte Antigen Workshop (CLAW). Tissue Antigens, Copenhagen, v.43, n.3, p.137154, 1994.

CREEVY, K.E. et al. Mixed chimeric hematopoietic stem cell transplant reverses the disease phenotype in canine leukocyte adhesion deficiency. Veterinary Immunology and Immunopathology, Amsterdam, v.95, n.3-4, p.113$121,2003$.

DAVIS, B.H.; BIGELOW, N.C. Flow cytometry reticulocyte quantification using thiazole orange provides clinically useful reticulocyte maturation index. Archives of Pathology \& Laboratory Medicine, Chicago, v.113, n.6, p.684-689, 1989.

DE KOK, I.J. et al. Investigation of allogeneic mesenchyma stem cell-based alveolar bone formation: preliminary findings. Clinical Oral Implants Research, Copengahen, v.14, n.4, p.481-489, 2003

DORE, M. et al. Production of a monoclonal antibody against canine GMP-140 (P-selectin) and studies of its vascular distribution in canine tissues. Veterinary Pathology, Middleton, v.30, n.3, p.213-222, 1993. 
EVANS, G.O.; FAGG, R. Reticulocytes counts in canine and rat blood made by flow cytometry. Journal of Comparative Pathology, Liverpool, v.111, n.1, p.107-111, 1994.

FALDYNA, M. et al. Lymphocyte subsets in peripheral blood of $\operatorname{dogs}$ - a flow cytometric study. Veterinary Immunology and Immunopathology, Amsterdam, v.82, n.1-2, p.23-37, 2001.

FALDYNA, M. et al. Flow cytometric analysis of bone marrow leukocytes in neonatal dogs. Veterinary Immunology and Immunopathology, Amsterdam, v.95, n.3-4, p.165-176, 2003.

FERGUSON, D.J. et al. Evaluation of reticulocyte by flow cytometry in a routine laboratory. American Journal of Hematology, New York, v.33, n.1, p.13-17, 1990.

GENGOZIAN, N. Identification and isolation of hemopoietic progenitors. In: FELDMAN, B.F. et al. Schalm's veterinary hematology. Philadelphia: Williams \& Wilkins, 2000. cap.16. p. 91-96.

GOERNER, M. et al. The use of granulocyte colony-stimulating factor during retroviral transduction on fibronectin fragment $\mathrm{CH}$ 296 enhances gene transfer into hematopoietic repopulating cells in dogs. Blood, New York, v. 94, n. 7, p. 2287-2292, 1999.

GRINDEM, C.B. Blood cell markers. Veterinary Clinics of North America: Small Animal Practice, Philadelphia, v.26, n.5, p.10431065, 1996.

HARTNETT, B.J. et al. Transplantation of X-linked sever combined immunodeficient dogs with $\mathrm{CD} 34^{+}$bone marrow cells. Biology of Blood and Marrow Transplantation, Charlottesville, v. 8 , n. 4 , p. $188-197,2002$.

HE, H. et al. Canine endothelial progenitor cell-lined hybrid vascular graft with nonthrombogenic potential. Journal of Thoracic and Cardiovascular Surgery, Saint Louis, v. 126, n. 2, p. 455-464, 2003.

HOGENESCH, H. et al. Effect of age on immune parameters and the immune response of dogs to vaccines: a cross-sectional study. Veterinary Immunology and Immunopathology, Amsterdam, v. 94, n. $1-2$, p. $77-85,2004$

HUSS, R. et al. Evidence of peripheral blood-derived, plasticadherent CD34 (-/low) hematopoietic stem cell clones with mesenchymal stem cell characteristics. Stem Cells, Basel, v.18, n.4, p.252-260, 2000.

KEREN, D.F. History and evolution of surface marker assays. In: KEREN, D.F. et al. Flow citometry and clinical diagnosis. Chicago: American Society of Clinical Pathologists, 1994, p.1.

KOVACIC, J.C. et al. Stem-cell therapy for myocardial diseases. Lancet, London, v. 363, n. 9422, p. 1735-1736, 2004.

KRISTENSEN, A.T. et al. Comparison of microscopic and flow cytometric detection of platelet antibody in dogs suspected of having immune-mediated thrombocytopenia. American Journal of Veterinary Research, Chicago, v.55, n.8, p.1111-1114, 1994.

LUNN, D.P. et al. Summary report of the Second Equine Leukocyte Antigen Workshop. Veterinary Immunology and Immunopathology, Amsterdam, v.54, n.1-4, p.159-161, 1996.

MATSUMURA, G. et al. First evidence that bone marrow cells contribute to the construction of tissue-engineered vascular autografts in vivo. Circulation, Baltimore, v. 108, n. 14, p. 1729-1734, 2003.

McGURRIN, M.K. et al. Flow cytometric detection of plateletbound antibody in three horses with immune-mediated thrombocytopenia. Journal American of Veterinary Medical Association, Chicago, v.224, n.1, p.83-87, 2004.

McSWEENEY, P.A. et al. Canine CD34: cloning of the cDNA and evaluation of an antiserum to recombinant protein. Blood, New York, v.88, n.6, p.1992-2003, 1996.

McSWEENEY, P.A. et al. Characterization of monoclonal antibodies that recognize canine CD34. Blood, New York, v.91, n.6, p.1977-1986, 1998.

MORITZ, A. et al. Flow cytometric detection of activated platelets in the dog. Veterinary Clinical Pathology, Baton Rouge, v.32, n.1, p.6-12, 2003.

NAESSENS, J. et al. Nomenclature and characterization of leukocyte differentiation antigens in ruminants. Immunology Today, Amsterdam, v.18, n.8, p.365-368, 1997.

NAKAGE, A.P.M. et al. Células-tronco no sangue do cordão umbilical de cães. In: CONGRESSO BRASILEIRO DE CLÍNICOS VETERINÁRIOS DE PEQUENOS ANIMAIS, 25., Gramado, RS, Anais... Gramado: Associação Nacional de Clínicos Veterinários de Pequenos Animais, 2004. V.1.100p. p.82-83.

NIEMEYER, G.P. et al. Isolation and Characterization of canine hematopoietic progenitor cells. Experimental Hematology, Amsterdam, v.29, n.6, p.686-693, 2001.

PAXTON, H. et al. Results of the flow cytometry ACTG quality control program: analysis and findings. Clinical Immunology and Immunopathology, Orlando, v.52, n.1, p.68-84, 1989.

QUIRKE, P.; DYSON, J.E.D. Flow cytometry: methodology and applications in pathology. Journal of Pathology, London, v.149, n.2, p.79-87, 1986.

REAGAN, W.J. et al. Flow cytometry analysis of feline reticulocytes. Veterinary Pathology, Middleton, v.29, n.6, p.503508, 1992.

RIVAS, A. L. et al. Characterization of monoclonal antibodies directed to canine $\mathrm{T}$ lymphocyte markers expressed during development. Veterinary Immunology and Immunopathology, Amsterdam, v. 51, n. 1-2, p. 1-11, 1996.

ROCHA, V. et al. Influence of bone marrow graft lymphocyte subsets on outcome after HLA-identical sibling transplants. Experimental Hematology, Copenhagen, v.29, n.11, p.13471352, 2001.

ROITT, I. et al. Imunologia. São Paulo: Manole, 1999. 424p.

RUF, A.; PATSCHEKE, H. Flow cytometric detection of activated platelets: comparison of determining shape change, fibrinogen binding, and $\mathrm{P}$-selectin expression. Seminars in Thrombosis and Hemostasis, New York, v.21, n.2, p.146-151, 1995.

RUSSEL, K.E. et al. Flow cytometric method for detecting thiazole orange-positive (reticulated) platelets in thrombocytopenic horses. American Journal of Veterinary Research, Chicago, v.58, n.10, p.1092-1096, 1997.

Ciência Rural, v.35, n.4, jul-ago, 2005. 
SANDMAIER, B.M. et al. Allogeneic transplants of canine peripheral blood stem cells mobilized by recombinant canine hematopoietic growth factors. Blood, New York, v.87, n.8, p.3508-3513, 1996 .

SANDMAIER, B.M. et al. Dog leukocyte antigenhaploidentical stem cell allografts after anti-CD44 therapy and reduced-intensity conditioniting ina preclinical canine model. Experimental Hematology, Copenhagen, v. 31 , n.2, p. $168-175,2003$.

SAALMULLER, A. Characterization of swine leukocyte differentiation antigens. Immunology Today, Amsterdam, v.17, n.8, p.352-354, 1996

SHIONO, H. et al. Accelerated binding of autoantibody to red blood cells with increasing anaemia in cattle experimentally infected with Theileria sergenti. Journal of Veterinary Medicine. B, Infectious Diseases and Veterinary Public Health, Berlin, v.51, n.1, p.39-42, 2004

SIENA, S. et al. Circulation of $\mathrm{CD} 34^{+}$hematopoietic stem cells in the peripheral blood of high-dose cyclophosphamide-treated patients: enhancement by intravenous recombinant human granulocyte-macrophage colony-stimulating factor. Blood, New York, v.74, n.6, p.1905-1914, 1989 .

STELZNER, M. et al. Identification of optimal harvest sites of ileal stem cells for treatment of bile acid malabsorption in a dog model. Journal of Gastrointestinal Surgery, Baltimore, v.7, n.4, p.516-522, 2003.

VULLIET, P.R. et al. Intra-coronary arterial injection of mesenchymal stromal cells and microinfarction in dogs. Lancet, London, v.363, n.9411, p.783-784, 2004

WANER, T. et al. Demonstration of serum antiplatelet antibodies in experimental acute canine ehrlichiosis. Veterinary Immunology and Immunopathology, Amsterdam, v.48, n.1-2, p.177-182, 1995

WEIBLEN, G.S. et al. "Acquired immunodeficiency" of blood stored overnight. New England Journal of Medicine, Boston, v.309, n.13, p.793, 1983

WEISS, D.J. Platelet products defects. In: FELDMAN, B.F et al. Schalm's veterinary hematology. Philadelphia: Williams \& Wilkins, 2000. Cap.66, p.469-471.

WEISS, D.J. Application of flow cytometric techniques to veterinary clinical hematology. Veterinary Clinical Pathology, Baton Rouge, v.31, n.2, p.72-82, 2002.

WEISS, D.J. Flow cytometric evaluation of canine bone marrow based on intracytoplasmic complexity and CD45 expression. Veterinary Clinical Pathology, Baton Rouge, v.33, n.2, p.96-101, 2004

WEISS, D.J. et al. Evaluation of platelet activation and platelet-neutrophil aggregates in ponies with alimentary laminitis. American Journal of Veterinary Research, Chicago, v.58, n.12, p.1376-1380, 1997.

WEISS, D.J. et al. Flow cytometric evaluation of canine bone marrow differential cell counts. Veterinary Clinical Pathology, Baton Rouge, v.29, n.3, p.97-104, 2000

WEISS, D.J.; TOWNSEND, E. Evaluation of reticulated platelets in dogs. Comparative Haematology International, v.8, n.3, p.166-170, 1998.

WILKERSON, M.J. et al. Isotype specific antibodies in horses and dogs with immune mediated hemolytic anemia. Journal of Veterinary Internal Medicine, Philadelphia, v.14, n.2, p.190196, 2000

WILKERSON, M.J. et al. Platelet surface associated IgG and reticulated platelets in dogs with thrombocytopenia Veterinary Clinical Pathology, Baton Rouge, v.30, n.3, p.141-149, 2001

WILLETT, B.J. et al. Identification of a putative cellular receptor for feline immunodeficiency virus as the feline homologue of CD9. Immunology, Oxford, v.81, n.2, p.228233, 1994

WOO, J.C.; MOORE, P.F. A feline homologue of CD1 is defined using a feline specific monoclonal antibody. Tissue Antigens, Copenhagen, v.49, n.3, p.244-251, 1997.

WYATT, C.R. et al. A flow cytometric method for assessing viability of intraerythrocytic hemoparasites. Journal of Immunological Methods, Amsterdam, v.140, n.1, p.23-30, 1991. 